\title{
Ecoturismo na fronteira pan-amazônica: possibilidades de gestão local em áreas protegidas do Brasil, Colômbia e Peru
}

\author{
Ecotourism in pan-amazonic frontier: possibilities of local \\ management in protected areas of Brazil, Colombia and Peru
}

\author{
Paulo Moreira Pinto
}

\section{RESUMO}

O contexto histórico da atividade turística permite compreender que a mesma vem paulatinamente tomando fôlego e se estabelecendo como importante para o desenvolvimento socioeconômico dos países. Na contemporaneidade, pode-se afirmar que o turismo se tornou política de Estado e um dos setores impulsionadores principais dos negócios ligados ao capital turismo. Entretanto, vêse que a variabilidade da gestão e as sucessivas mudanças dos entes institucionais que abrigaram o turismo impuseram descontinuidades. Na conjuntura dessas transformações, segmentos novos do mercado turístico foram sendo valorizados tendo em vista o crescimento da demanda e as mudanças ideológicas dos consumidores. Ressalte-se que esses processos ocorrem com a valorização dos locais turísticos como chave de desenvolvimento endógeno, uma vez que o entendimento era estimular que os ganhos do turismo permanecessem na localidade de compra e de consumo turístico. Essa inversão ocorre no cerne do processo de globalização econômica e da liberalização de mercado, além da condicionante da questão da conservação ambiental. No âmbito dessas transformações, a sustentabilidade destaca-se, em suas vertentes teórica e prática, como elemento importante para as experiências políticas de organização e gestão local sucessivas. Desta maneira, a gestão local toma impulso enquanto estratégia de Estado para mitigação dos impactos ocasionados por atividades depredadoras, principalmente na Amazônia e Pan-Amazônia, via pressões das agências de investimento internacionais. O processo de globalização econômico-financeira e a busca por mercados novos de commodities reforça o sentido da conservação dos recursos naturais e, nesse sentido, ganha força o modelo de criação de Áreas Protegidas (AP). Tal modelo está centrado em uma condição mítica de natureza intocada que provoca conflitos com as populações residentes no interior e no entorno das AP e rivaliza com a lógica da gestão local. Na fronteira pan-amazônica do Brasil, Colômbia e Peru, a problemática adquire componentes diferenciados, com a presença de povos indígenas e dos aspectos da multiculturalidade, que preconizam debates inovadores. Nesse sentido, fez-se análise comparativa entre as AP localizadas na tríplice fronteira de cujos resultados ressaltam as diferenças e similitudes dos processos de adoção do ecoturismo e da gestão local nos loci estudados.

PALAVRAS-CHAVE: Ecoturismo; Gestão Local; Áreas Protegidas; Pan-Amazônia. 


\section{ABSTRACT}

The historic context of the touristic activity allows a comprehension that this is slowly becoming strong and establishing itself as important to the socio-economic development to all countries. In the contemporaneity, one can affirm that tourism became a State Policy and one of the principal sectors that booster the business linked to tourism as capital. However, it is seen that the variability of management and the successive transformations of the institutional identities that included the tourism generated discontinuities. In the conjuncture of such transformations, new segments of the touristic market were being valued regarding the growing demands and the ideological changes of the consumers. It should be noted that this occurs with the valorization of touristic places as key to endogenous development, as the purpose was to stimulate that the gains of tourism remain in the locality of the touristic consuming's acquisition. Such inversion happens in the center of the process of economic globalization and of the market liberalization, this besides the conditioning of the environmental conservation question. In the scope of these transformations, the sustainability is highlighted, in its theoretical and practical approaches, as an important element to the successive political experiences in organization and local management. In this manner, a local management takes impulse while a State strategy to mitigate the impacts created by predatory activities, mainly in the Amazon and the Pan-Amazon, through pressures of the international investments' agencies. The economic-financing globalization's process and the search for new markets of commodities reinforce the sense of conservation of the natural resources, and in this direction gains strength the model of creation of Protected Areas (AP). Such model is centered in the mythical condition of untouchable nature that causes conflicts with the resident populations of the interior and surroundings of the AP and rivalizes with the local management logic. In the Pan-Amazonic frontier of Brazil, Colombia and Peru, the problematic acquires diverse components, with the presence of Indigenous peoples, of aspects of multiculturality that recommend innovating debates. In this direction, it was done a compared analysis between the AP localized in triple frontier and the results stressed the differences and similarities of the adoption of ecotourism's process and of the local management in the studied loci.

KEYWORDS: Ecotourism; Local Management; Protected Areas; Pan-Amazon.

\section{Introdução}

No Brasil, o bioma Amazônia ${ }^{1}$ tem registrado uma trajetória que o inclui como reservatório de uma biodiversidade incomensurável, sendo que a sua salvaguarda é condição sine qua non para a manutenção do planeta. Portanto, a sua inserção no imaginário global tem proporcionado abordagens distintas e ensejado investigações com propósitos os mais diferenciados. No caso do turismo, tem crescido as perspectivas por experiências de gestão local nas Áreas Protegidas (AP). Tal realidade tem provocado a proposição de políticas públicas que intentam reduzir os conflitos no interior e no entorno das AP amazônicas.

$\mathrm{Na}$ Pan-Amazônia, o cenário é similar, principalmente nas AP localizadas na tríplice fronteira do Brasil, Colômbia e Peru, criadas por políticas de Estado com a mesma proposta de conservação dos recursos 
naturais, obviamente com diferentes particularidades, mas com o intento de prevenir e ou resolver conflitos semelhantes. Como se observará, com a adoção da atividade turística buscou-se aglutinar ações cooperativas no interior das comunidades ${ }^{2}$ como elemento diferenciador. As possibilidades resultantes disso necessitam ser examinadas comparativamente como maneira de indicar orientações a serem seguidas em busca de ações inovadoras e condizentes com o ambiente pan-amazônico e com os anseios dos pan-amazônidas.

Enquanto questão nova e que enseja estudos amplos, a criação de AP associa-se, historicamente, à cosmovisão de sociedades ancestrais sobre a natureza (MILLER, 1997). Posteriormente, com as mudanças ocorridas na maneira de se lidar com os recursos naturais, estes passam a ser contabilizados como capital natural (SÁNCHEZ ALBAVERA, 1993). Portanto, a estratégia de criação das AP também está ligada a uma concepção nova de patrimônio natural, o que corresponde à posturas ideológicas marcadas pelos processos de globalização econômica, cultural e ambiental.

No caso das AP implantadas no bioma Amazônia, reconhecido internacionalmente por sua importância para a sustentabilidade planetária, a busca é por estratégias que minimizem os impactos antrópicos negativos. Deste modo, a Amazônia e também a Pan-Amazônia passam a configurar loci privilegiados de pesquisa. $E$ isso no intuito de explicar os conflitos que se desenrolam com problemáticas as mais diferentes.

Neste contexto, as instituições de ensino e pesquisa da Amazônia e Pan-Amazônia ${ }^{3}$ têm produzido estudos paradigmáticos que estão a revelar as implicações do turismo com os impactos biossocioculturais (SIMONIAN; PINTO; CAMPOS, 2007). De todo modo, aponta-se que a direção tomada por essas pesquisas é a de uma reflexão crítica sobre o discurso oficial e politicamente correto, cuja tendência é a de demonstrar as implicações positivas da atividade turística. Para tanto, se utilizam de estratégias teóricometodológicas que encaminhem as análises para uma conjunção dos saberes disciplinares.

Trata-se de seguir as pistas deixadas por estudos de teóricos diversos que contribuem para o avanço das pesquisas em turismo. Tal fato denota que a investigação a ser realizada flui em paralelo, mas não exatamente no mesmo sentido as já executadas. Nesse caso, o problema a ser investigado está inserido em área da porção territorial da floresta tropical úmida, na Amazônia ocidental, nas AP Terra Indígena (TI) Tukuna Umariaçu ${ }^{4}$, em Tabatinga, Parque Nacional Natural (PNN) Amacayacu, em Letícia, e na Reserva Nacional (RN) Pacaya Samiria, em lquitos, ou seja, na tríplice fronteira do Brasil, Colômbia e Peru, respectivamente.

É evidente que conflitos variados surgem desta relação, pelas questões mais diferentes, que vão desde a posse de terras e sua legalização; e até o desenvolvimento de atividades econômicas que se incorporem à condição local e o acesso às tecnologias novas em um mundo globalizado. No território constitutivo da tríplice fronteira do Brasil, Colômbia e Peru, o turismo é projetado, como no mundo todo, como alternativa de 
desenvolvimento econômico e, em muitos casos, trabalhado como monocultura, o que por si só já demonstra um engano teórico e prático.

\section{A tríplice fronteira pan-amazônica}

As AP em estudo localizam-se na região da denominada tríplice fronteira ${ }^{5}$ do Brasil, com a Colômbia e o Peru, aonde se encontram segmentos urbanos fronteiriços; algumas destas cidades correspondem ao

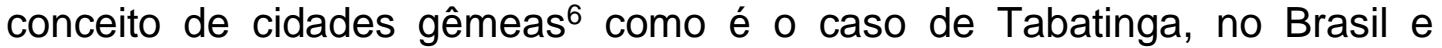
Letícia, na Colômbia. Esta parte mais ocidental da Amazônia vem sendo alvo de investigações desde os primórdios da colonização de origem europeia, ${ }^{7}$ mas principalmente a pelo menos quatro décadas e com interesses diversos. De maneira geral, pode-se afirmar que vem sendo palco de intervenções de caráter distinto, as quais refletem de modo micro o macrocosmo das ações imputadas pelo desenvolvimento econômico globalizado.

A tríplice fronteira é uma área bastante militarizada com a presença ostensiva dos grupamentos nas cidades e no percurso dos rios que servem de limites naturais aos três países. As áreas enfiteutas estão presentes nas cidades de Tabatinga e Leticia ocupadas por bases militares com intuito de assegurar as Políticas de Defesa Nacionais respectivas. Também, a justificativa disso se faz a partir do comércio ilegal das riquezas minerais, vegetais, animais e do tráfico de drogas amplamente publicizados no sentido de cooptar a opinião pública.

$\mathrm{Na}$ fronteira pan-amazônica, os países esperam por marcos regulatórios vindos do governo central. Na maioria das vezes tais comandos espelham apenas a condição de posse das fronteiras pela segurança do território sem consequências no modus vivendi e operandi das populações que ali habitam ou transitam. Reflexo disso são as mudanças ocorridas na estrutura urbana e populacional das cidades fronteiriças ${ }^{8}$ principais como Tabatinga, no Brasil; Leticia, na Colômbia; e lquitos, no Peru, que se transformaram em loci privilegiados de investigação científica a partir das AP implementadas, que podem ser visualizadas na Figura 1 (próxima página).

Em que pese serem AP de categorias de manejo diferentes - TI, PNN e $\mathrm{RN}$ - possuem um aspecto em comum: são territórios habitados por grupos indígenas de etnias diversas, com destaque maior para os do grupo Tikuna ${ }^{9}$. Embora sem informações precisas sobre a sua quantidade, os Tikuna encontram-se espalhados pelos três países, sendo que a concentração mais elevada está entre os que habitam o estado do Amazonas. Investigações realizadas por Oliveira Filho (1988) e Oliveira (1978) explicitam os impasses sofridos por essa população indígena ao longo do tempo, principalmente em sua relação com o Estado escravizador e usurpador de seu território. 


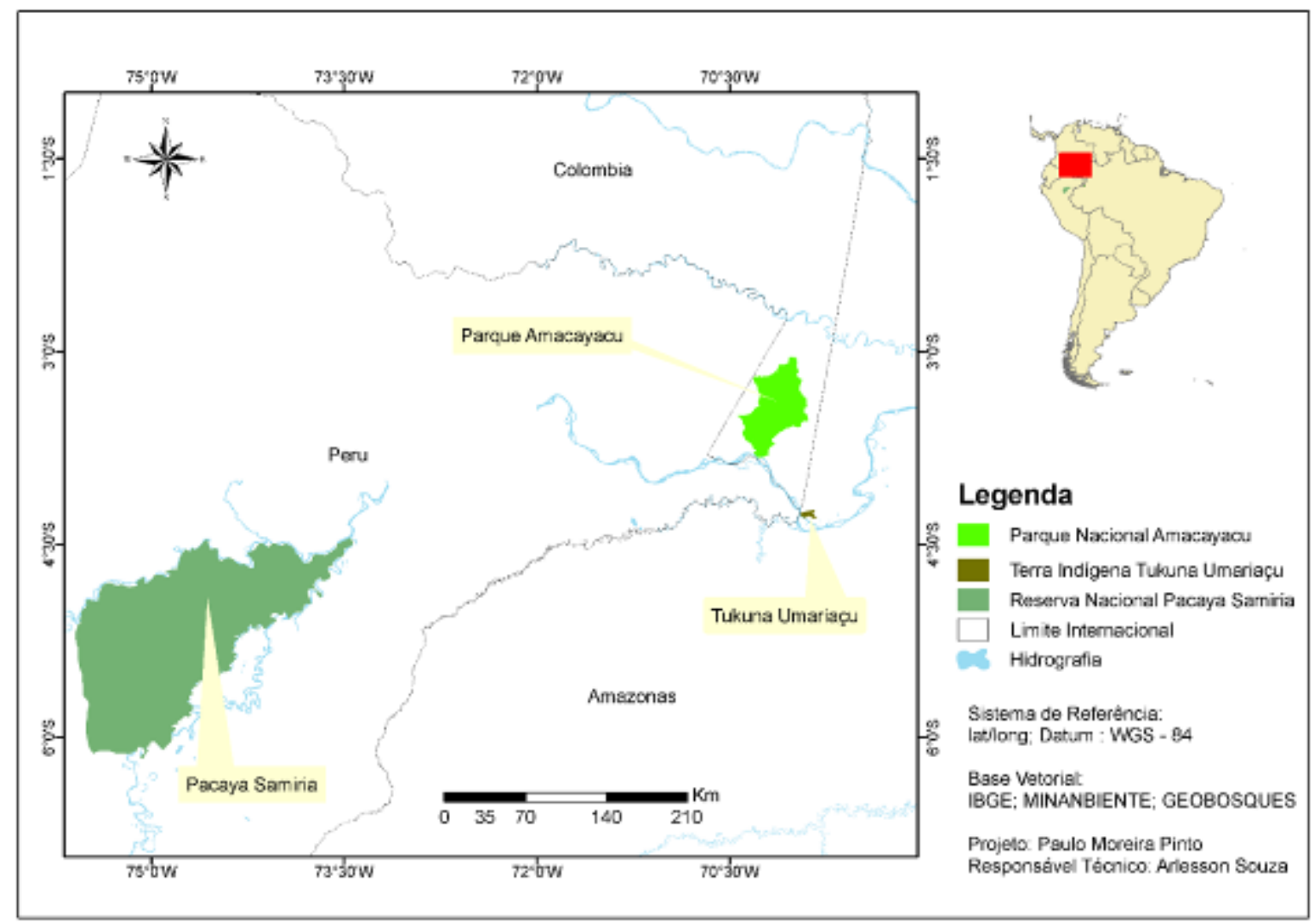

Figura 1: Localização das Areas Protegidas em estudo.

Figure 1: Location of Protected Areas under study.

Fonte: Paulo M. Pinto (2016).

Source: Paulo M. Pinto (2016).

No Brasil e como descrita no Decreto $s / n$, de 11 de dezembro de 1998, que homologa a demarcação administrativa promovida pela Fundação Nacional do Índio (FUNAI), a TI Tukuna Umariaçu encontra-se localizada no município de Tabatinga, estado do Amazonas, com área oficial de 4.854 hectares, em um perímetro aproximado de $38 \mathrm{Km}$, e é integrada pelas aldeias Umariaçu I e II e Cidade Nova. Nelas, convive uma população estimada em 7.219 habitantes (ISA, 2015), da família linguística Tikuna e que se autodenominam de Magüta.

Esta autodenominação foi descrita pelo etnólogo Curt Unkel Nimuendajú (1883-1945), e diz respeito à origem mítica do povo Tikuna. Em conformidade com estudos de Cruz (2006, p. 4), esta origem mítica narra que:

[...] Yo'i e Ipi criaram o povo Tikuna. Yo'i usando isca de macaxeira pescou no igarapé Évaré, peixes que se transformaram em gente ao serem retirados da água, conseguindo desta maneira, formar o povo Magüta, que quer dizer "povo pescado do rio", dos quais descendem os Tikuna. Ipi também pescou muita gente, só que não era povo Magüta [...]. 
Portanto, de acordo com Oliveira-Filho, (1988, p. 146) "Magüta é a primeira geração de homens pescados por Yoi e Ipi [...]". Por meio desse mito de criação do mundo, pode-se compreender o processo de luta dos Tikuna para reconhecimento de seu território e não só como fonte de subsistência, mas também como local sagrado onde habitam os criadores desse povo.

Na Colômbia, o PNN Amacayacu foi criado por força do Acordo n. 40, de 30 de setembro de 1975 e aprovado pela Resolução Executiva n. 0283, de 27 de outubro de 1975. Está situado em área da jurisdição dos municípios de Leticia (ao sul e leste), Puerto Nariño (a oeste) e o corregimiento departamental de Tarapacá (ao norte). Localiza-se no setor meridional do trapézio amazônico, entre os rios Amazonas ao sul e Cotuhé ao norte; a oeste com o rio Amacayacu e as quebradas Cabimas e Pamaté; a leste com a quebrada de Lorena, o caño Murcia, rio Purité e a quebrada Matamatá.

A história do parque tem início com a demarcação dos 170.000 hectares da Reserva Forestal de la Amazonía que, em 1987, pelo Acordo n. 0092, de 15 de dezembro de 1987, aprovado pela Resolução Executiva n. 0092, de 11 de fevereiro de 1988, teve redefinida sua área para os 293.500 hectares atuais. A gestão é realizada pelo Sistema de Parques Nacionales Naturales (SPNN), criado pelo Decreto n. 622 de 1977. Porém, com a aprovação da Lei n. 99 de 1993, a administração das áreas passa a ser competência da Unidad Administrativa Especial del Sistema de PNN $(\text { UAESPNN })^{10}$, órgão do Ministério de Ambiente, Vivienda y Desarrollo Territorial (MINAMBIENTE).

No Peru, a RN Pacaya Samiria foi criada pelo Decreto Supremo n. 016-82-AG, de 4 de fevereiro de 1982, estendendo-se por área de 2.080 .000 hectares do Departamento de Loreto, compreendendo parte das províncias Alto Amazonas, Ucayali, Loreto e Requena e seus respectivos distritos. Em consonância com o Plan Maestro 2009-2013 verifica-se que a sua história inicia pela proteção do Pirarucu (Arapaima gigas), como se depreende de documento do Sistema Nacional de Áreas Naturales Protegidas por el Estado (SINANPE, 2009, p. 7):

Se estableció originalmente como Zona Reservada, en la cuenca del rio Pacaya, en el año de 1940, con el fin de proteger el Paiche (Arapaima gigas), el pez de agua dulce más grande del mundo. Actualmente protege la totalidad de la cuenca de los ríos Pacaya y Samiria. La Reserva Nacional Pacaya Samiria protege la mayor extensión de bosque inundable en la Amazonía peruana y ofrece una riqueza de recursos a la población humana presente en el área. El estilo de vida de la mayor parte de sus habitantes es de subsistencia, dependiendo su calidad de vida, de la conservación de los recursos naturales que los rodean. 
Dessa feita, vê-se que o processo de planejamento já é bastante utilizado, e já vem acontecendo desde o ano de 1986.

Então e em conformidade com o documento oficial, já estabelecia a participação integrada da população. Além disso, contava-se com apoio técnico e financeiro de diversas entidades internacionais como o World Wilde Fund (WWF), The Nature Conservancy (TNC), entre outras. E note-se, o Plan Maestro foi aprovado no ano de 2000 foi revisto com base em estratégias do planejamento participativo.

\section{Ecoturismo e sustentabilidade em Áreas Protegidas}

$\mathrm{Na}$ contemporaneidade, o termo sustentabilidade vem sendo empregado como prefixo de suporte para diferentes assertivas, como maneira de demonstrar uma faceta nova para categorias já conhecidas, tais como: sustentabilidade socioeconômica, cultural, ambiental, turística etc. Trata-se, portanto, de uma tendência que minimamente tenta impulsionar uma reflexão sobre as condicionantes do processo de desenvolvimento. Por sua vez, o desenvolvimento é o corolário de muitos processos que vão desde a sua qualidade física (estrutura) até a sua condição anímica (emocional).

Do ponto de vista teórico, o desenvolvimento e a sustentabilidade vêm sendo alvos de reflexões em campos de estudo diferentes, como na Economia, na Geografia, na Ciência Política, na Comunicação, na Antropologia etc. Nessa última, inclusive, configura um campo de conhecimento novo denominado de Antropologia do Desenvolvimento, cujo cerne são as contradições do desenvolvimento sobre as condições de existência da sociedade ${ }^{11}$. Tais contradições provocaram mudanças nas demandas sociais, pelos acontecimentos catastróficos ocorridos em partes diversas do planeta, os quais demonstraram a possibilidade de finitude dos recursos naturais.

Esta possibilidade engendra uma lógica nova à racionalidade econômica imposta a todos via os processos de globalização, dando início a debates diferenciados acerca das alternativas de desenvolvimento e das políticas inovadoras a serem elaboradas com base nesta lógica. Historicamente, esse cenário situa-se entre as duas grandes guerras mundiais e, posteriormente, foi condicionado por eventos que colocaram em xeque a possibilidade de o ser humano impedir ocorrências nefastas à humanidade. Dessa maneira, emergem as discussões sobre políticas de desenvolvimento que sejam mais satisfatórias às aspirações das populações e da reconfiguração mundial nova.

Neste sentido, a política ambiental vem praticando - de maneira globalizada - exercícios de sustentabilidade nas propostas de conservação dos recursos naturais, dentre as quais a de criação de AP. Enfatize-se que, no Brasil, o termo utilizado pela política ambiental é o de Unidade de Conservação (UC) que por muitos é tomado por sinônimo daquele. Porém, conceitualmente, existe diferença entre os termos sendo que AP é a nomenclatura reconhecida internacionalmente e, portanto, com utilização em espectro largo. O termo UC é utilizado no Brasil como categoria de manejo 
das AP, entretanto, na Colômbia e no Peru'12, a denominação usada é a nomenclatura aceita internacionalmente.

Nos países da América Latina, o termo sustentabilidade tem dado suporte a segmentos diferentes do denominado turismo de natureza ${ }^{13}$, principalmente o ecoturismo que se trata de uma tendência nova do mercado turístico. McKercher (2002) enfatiza que são atividades as mais diversas inseridas no turismo de natureza, a maioria delas rotuladas como ecoturismo, o que denota desconhecimento teórico e prático. Nesse contexto, as políticas elaboradas na maioria dos países utilizam o termo ecoturismo como sinônimo de Turismo Sustentável (TS).

Nas AP da tríplice fronteira do Brasil, Colômbia e Peru, o TS aparece como componente do ecoturismo nas políticas elaboradas para 0 desenvolvimento da atividade. As estratégias de ação para a sustentabilidade biossociocultural dessas áreas estão centradas no desenvolvimento do ecoturismo como uma das propostas de atividade para incluir a participação comunitária na administração e gestão. Tal fato estimulou, inclusive, mudanças no âmbito das instituições que incorporam o termo sustentabilidade em sua nomenclatura e na missão do ente estatal.

Apesar da existência de diferenças históricas e culturais entre os países da tríplice fronteira, o modelo de políticas de sustentabilidade e os aparatos institucionais estão presentes mutatis mutandis na Colômbia e no Peru. Como no Brasil, os organismos se dispõem hierarquicamente, a partir de um ente em nível de Ministério que elabora as políticas e cria um sistema para administrá-las e geri-las. Nos três países, a elaboração e a execução do plano de manejo são critérios para a administração e gestão das AP.

A inclusão do TS no planejamento das atividades dos destinos turísticos - quer sejam AP ou outros - segue as diretrizes estipuladas pela Organização Mundial do Turismo (OMT), que estimula o envolvimento de muitos atores no processo. A premissa é a de que "a cooperação entre todos esses parceiros é essencial para a conquista do turismo próspero e sustentável' (OMT, 2003, p. 33). Nesse caso, pressupõe a constituição de um fórum amplo que envolva os proprietários e gerentes dos empreendimentos comerciais de turismo, os apoiadores das causas ambientais - os defensores da conservação ambiental e a comunidade residentes, grupos e líderes comunitários e as autoridades locais.

No caso das AP da tríplice fronteira pan-amazônica, a existência de povos indígenas faz com que os elementos de sustentabilidade tenham que estar consoantes com a preservação das tradições e das identidades culturais locais. Por esse motivo, o TS tem a propensão a adotar 0 ecoturismo, que pode ser praticado sob o domínio dos recursos locais. Segue-se, assim, o princípio norteador do TS que é o de "[...] maximizar o divertimento dos visitantes e os benefícios locais, minimizando, ao mesmo tempo, os impactos negativos sobre a comunidade do local de destino e a sua população [...]" (OMT, 2003, p. 109), princípio nem sempre alcançado em virtude da preponderância dos impactos negativos sobre os positivos. 
Nas AP da tríplice fronteira, o TS segue a normativa prescrita pela OMT e União Internacional para a Conservação da Natureza (IUCN, da sigla em inglês), principalmente na Colômbia e no Peru, porém, vê-se que ainda há um longo caminho a se percorrer para atingir níveis maiores de sustentabilidade. Nesses dois países, o TS está presente nos documentos oficiais e nos planos, programas e projetos de desenvolvimento da atividade, sejam de iniciativa pública ou particular. $E$, também, está incluído como elemento dos "Planes de Vida" elaborado pelos indígenas para fazer frente as suas reivindicações junto aos governos constituídos em suas diferentes esferas de atuação.

No Brasil, a incorporação da perspectiva do TS nos planos de manejo das AP é uma prerrogativa desde meados dos anos 1980, embora, a maioria das AP brasileiras não disponha de planos de manejo elaborados. No tocante às $\mathrm{TI}$, não há exigência de um plano de manejo enquanto documento formalizado, no entanto, criou-se a Comissão Nacional de Desenvolvimento Sustentável dos Povos e Comunidades Tradicionais $(\text { CNPCT })^{14}$ por Decreto em 13 de julho de 2006. A partir daí vem sendo construída a Política Nacional de Desenvolvimento Sustentável dos Povos e Comunidades Tradicionais (PNPCT).

A PNPCT foi instituída pelo Decreto n. 6.040, de 07 de fevereiro de 2007, e estabelece a elaboração e implementação dos Planos de Desenvolvimento Sustentável dos Povos e Comunidades Tradicionais (PDSPCT). Consiste em um conjunto de ações que objetivam dar suporte à política e serem incluídos no Plano Plurianual de governo com metas a serem atingidas em curto, médio e longo prazo. Apesar de os indígenas estarem incluídos no conceito de povos e comunidades tradicionais, definidos nos termos da legislação, a norma abarca categorias diversas distanciando-se das questões específicas.

Tal amplitude deixa lacunas e pontos de divergência na execução da norma no caso das TI, como é possível de se observar no caso da inserção de atividades como o turismo. Diferente do caso brasileiro, os PNN Amacayacu e RN Pacaya Samiria possuem planos de manejo elaborados e - TS está delimitado pela adoção do ecoturismo como atividade de desenvolvimento. $\mathrm{Na}$ TI Tukuna Umariaçu, diferentemente, a adoção da atividade turística ainda é fator de debate entre os comunitários e as diversas esferas de governo.

\section{Possibilidades de gestão local nas Áreas Protegidas pan-amazônicas}

A estratégia adotada pelo Estado para inclusão da problemática local é uma redefinição no sistema de planejamento, passando a inserir o componente participativo como maneira de legitimar as ações elaboradas. Assim, são chamados atores que operam como agentes demandantes e multiplicadores dessas ações que postulam o bem-comum e a participação democrática nos fóruns de decisão ${ }^{15}$. Nesse caso, as atenções se voltam para o local como fórum de decisão e campo ideológico de disputas e interesses dos mais diversos. 
Neste campo ideológico, as demandas vão se ampliando para as esferas da administração e da gestão da coisa pública e o sistema de mercado absorve o que pode e acredita necessário para a sua reprodução. Entretanto, quase sempre se trata de uma estratégia de cooptação, como expõe Albagli (2005, p. 20):

[...] os conhecimentos de comunidades locais, incluindo povos indígenas e outras populações tradicionais, passam a despertar um interesse crescente nas indústrias que atuam em áreas associadas às biotecnologias, ao servirem como verdadeiros "atalhos" para as atividades de bioprospecção.

Assim, ressalta-se o local como o campo das culturas tradicionais ${ }^{16}$, não contaminadas por processos homogeneizantes de mercado, e que precisam ser valorizadas. Tal fato possibilita uma redefinição no sentido da participação dos comunitários nos processos de gestão em virtude do seu conhecimento ancestral sobre determinado território e seus recursos naturais.

Este reconhecimento não se faz pacificamente entre os dois lados da questão, os conflitos são provenientes tanto do Estado, quanto das populações que se mobilizam em torno da resolução de um determinado problema. No caso da criação de AP, como por exemplo a homologação de uma TI que é realizada pelo poder público, mas a gestão é feita pelos índios. Nesse sentido, é importante a elaboração do documento chamado plano de manejo que define as atividades que podem ser realizadas nas AP, em conformidade com o seu grupo e a categoria de manejo. É também através do plano de manejo que se estruturam os fóruns de gestão.

É óbvio que apenas a elaboração do plano não é garantia de eficiência de gestão. Precisamente no caso das AP brasileiras, o poder público criou o Instituto Chico Mendes de Conservação da Biodiversidade (ICMBIO) para realizar a gestão. De onde se depreende que a gestão local é realizada pelas subunidades do ICMBIO, portanto não é comunitária.

A participação das comunidades se faz por meio de suas participações e representações nos conselhos ${ }^{17}$ gestores. Em certa medida, esses dependem da elaboração do plano de manejo. Embora o quadro da situação normativa das AP tenha tido um avanço, algumas situações como a falta de regulação fundiária emperram o processo, pois segundo informa Futada (2011), o conflito é generalizado pela presença de terras particulares no interior dessas áreas.

Desta feita, o uso público por meio do turismo vem sendo inserido nas AP brasileiras como "[...] uma das fontes de recursos potenciais para promover a sustentabilidade financeira do SNUC em geral e das UC, em particular" (FUTADA, 2011, p. 40). A saber, acordos diversos foram sendo firmados em vistas de estruturar o turismo, principalmente na categoria dos parques nacionais, culminando com o termo de reciprocidade assinado entre 
ICMBIO e a Associação Brasileira das Empresas de Ecoturismo e Turismo de Aventura (ABETA). O objetivo é estabelecer projetos conjuntos (FUTADA, 2011) de estruturação e gestão da visitação para os segmentos de turismo de aventura e de ecoturismo.

O ecoturismo tem sido referenciado pelas políticas públicas e pelo setor empresarial na Amazônia como "vocação" natural da região e, na PanAmazônia não poderia ser diferente, estudos paradigmáticos têm sido realizados para demonstrar os efeitos dessas políticas. Nesse aspecto, as pesquisas recentes realizadas por Campos (2008), Cruz (2010) e Quaresma (2008) enfatizam a importância que o desvendamento das implicações das políticas de turismo tem para o desenvolvimento da região. Tais referências auxiliam também na montagem de um cenário que tem como palco as AP e o turismo como uma das maneiras de se manejar essas áreas.

Neste contexto, as lutas pela criação de AP tomam fôlego e se expandem na Amazônia, pressionando o poder público no sentido da ampliação das conquistas e da legitimação dos movimentos sociais (SIMONIAN, 2000). Por pressão é criada uma política ambiental que busca atender aos pedidos da sociedade civil organizada que segundo Becker (2009, p. 104) é estabelecida com outra lógica, a saber:

Ao contrário da política das décadas anteriores, pautada em desenvolvimento e segurança, a política ambiental visa o desenvolvimento sustentável, fundamentando-se numa ação descentralizada e participativa para a qualidade de vida das populações locais. Certamente, há também interesses de controle da informação sobre o saber local e o próprio território pelos parceiros nacionais e internacionais.

Assim, cresce o interesse por políticas públicas cujo conteúdo atenda aos diferentes interesses e aos embates econômicos e político-ideológicos dos setores particulares (ligados ao capital) e as demandas por efetiva participação na gestão (ligadas aos movimentos sociais).

Deste confronto, são formuladas políticas públicas que tentam resgatar o modelo endógeno em uma alternativa de ampliação da participação das comunidades amazônicas. Assim, a participação em gestão local tem tomado força enquanto premissa inovadora em políticas públicas e, em AP, a inserção da atividade turística tem sido a propulsora dessa descentralização. Desde então, o local tem se firmado como centro de discussões e debates a procura de seu entendimento como categoria de análise das práticas adotadas.

Para a atividade turística, o poder local vem do contexto da adoção de políticas e programas que se fundamentam na descentralização administrativa e financeira. Entretanto, as práticas em comunidades de porte pequeno nem sempre lograram o êxito esperado, segundo apontam as pesquisas realizadas por Bursztyn, Bartholo e Delamaro (2009). Depreendese, então, de acordo com esses autores, que a busca de um modelo que se contraponha ao turismo de massa e que respeite as heranças culturais e 
tradições locais há de ter como premissa o Turismo de Base Comunitária (TBC).

Na Pan-Amazônia, em especial nos países da tríplice fronteira, a experiência colombiana em processos de turismo e gestão local, pode ser exemplificada com o que está expresso no Plan de Manejo do PNN Amacayacu. Do que está registrado no plano, pode-se inferir que, em aproximadamente 17 anos, o país vem desenvolvendo trabalhos de educação ambiental e ecoturismo. Nesse caso, o plano informa que:

Los procesos de investigación y monitoreo también se han implementado en la región y para el caso del parque desde hace 5 años, se incrementó su desarrollo. Al aumentar la presencia de estudiantes e investigadores se presentó inquietud por parte de las Comunidades entorno al deber ser de la investigación y su aporte a las mismas e incluso para la gestión del Área Protegida. Como resultado de este análisis conjunto o y bajo el auspicio do PNN Amacayacu y contando con el apoyo de la Fundación Tropenbos se definió la necesidad de propiciar un espacio para tocar el tema de la investigación en forma global, que derivo en la conformación del GTI, Grupo de Trabajo en Investigación, del cual hacen parte, las seis comunidades con las que se propone el manejo conjunto y concertado del territorio en el Sector Sur del Parque y su zona de influencia y el equipo del PNN Amacayacu (GOVERNO DA COLÔMBIA, [2004] 2013, p. 8).

Enfatize-se que nessa experiência os povos indígenas têm histórico político e sociocultural de luta contra a dominação e expropriação de seus territórios.

$\mathrm{Na}$ Colômbia, o segmento do ecoturismo foi tomado como fator de agregação dos comunitários, senão veja-se:

Dentro de las principales oportunidades del ecoturismo es que este se concibe en la región como una estrategia para vincular actores en la conservación poniendo en práctica algunos elementos del llamado desarrollo sostenible. [...]. Se espera poder potenciar estas oportunidades a través de la implementación de procesos periódicos de capacitación y formación dirigidos a las comunidades que redunden en un mejoramiento sustancial en la prestación de los diversos servicios ofrecidos en el área a los visitantes, brindando, de paso, una muy buena imagen que como resultado generen efectos multiplicadores para el ecoturismo y permitan ampliar la oferta ecoturística del parque (GOVERNO DA COLÔMBIA, [2004] 2013, p. 12). 
Do qual se depreende um discurso que necessita ser comprovado na prática, pois como se verá mais adiante, um consórcio de empresas particulares detém a possibilidade de administração e gestão da infraestrutura turística do PNN Amacayacu. Em consonância com informações oficiais, esse tipo de iniciativa tem sido exitosa para as comunidades envolvidas, porém investigação mais detalhada necessita ser realizada.

No Peru, um dos exemplos de diretrizes para o desenvolvimento de atividades turísticas estão contidas no Plan de Uso Turístico y Recreativo de la RN Pacaya Samiria e seguem o estabelecido no Plan Maestro RN Pacaya Samiria. Além destes, existe o documento Oportunidades para el Turismo en la RN Pacaya Samiria. Bastante minuciosos, tais documentos descrevem os "actores y grupos de interés" implicados na gestão da referida AP como: governo, população local, agências de viagens e empresas turísticas, ONG e instituições de cooperação internacional, guias de turismo, visitantes e turistas e as instituições financeiras.

Do ponto de vista da participação da população local na gestão da reserva, o plano de uso turístico enfatiza que: "La participación de las poblaciones locales en las actividades turísticas, desde su planificación hasta su ejecución y gestión, es un mecanismo que favorece su integración en las labores de gestión del áreas protegidas" (RESERVA, 2002, p. 16). Chama a atenção à relação de proximidade que há de se estabelecer entre a população e a administração da área para o desenvolvimento da atividade turística. Porém, esclarece que esta participação ainda não se consolidou e que implica na integração de todos os atores e grupos de interesse envolvidos.

No Peru, também são outorgadas concessões para empresas particulares explorarem os serviços turísticos e, segundo os registros do Plano, as empresas têm contribuído para o desenvolvimento da atividade. Enfatize-se, ainda, que empresas de caráter comunal também recebem autorizações para trabalhar com a atividade turística, ofertando serviços como de guias, alojamentos etc. Embora, ressaltem que existem conflitos internos que prejudicam o desenvolvimento eficaz da iniciativa.

\section{Considerações finais}

Ao se comparar as possibilidades de gestão em turismo nas AP selecionadas do Brasil, Colômbia e Peru têm-se panorama que, numa primeira análise, parece incompleto. Isto se deve ao fato de que no Brasil, diferente dos outros dois países, estes processos são de passado recente, apesar das múltiplas incursões estatais no campo do turismo, ou do ecoturismo, em $\mathrm{TI}$ ao longo do tempo. Do ponto de vista normativo, depreende-se que a visitação para fins turísticos em TI ainda se encontra em desenvolvimento.

Como se pôde perceber do contexto do turismo brasileiro, os processos de inserção comunitária na gestão de AP, principalmente em TI, indicam realidade a ser construída. As autoridades constituídas e responsáveis pela administração da política para os índios têm sido 
refratárias a permissão de atividades econômicas não-indígenas, potencialmente geradoras de conflitos. Embora se saiba que, por fatores diversos, muitas atividades ilegais têm ocorrido em TI, sem que o Estado tenha condições de freá-las.

Em que pese as dificuldades de fiscalização de ilícitos pelas instituições competentes, cabe comparar mutatis mutandis as possibilidades adotadas nas AP colombianas e peruanas. Embora não exista na legislação brasileira abertura para o modelo de concessão dos serviços turísticos a empresas particulares em TI, exercícios intelectuais podem ser realizados. Isso tendo em vista a normativa recente e os processos decorrentes da participação da população indígena na administração e gestão das atividades turísticas.

A seguir-se estas reflexões não cabem dúvidas sobre a possibilidade de considerar que o turismo tem influenciado o modus vivendi e operandi das populações locais na tríplice fronteira. A implicação das mesmas no espaço transfronteiriço é agudizada pelos processos políticos e ideológicos de mercado em sua via globalizada que denotam a impossibilidade de combate frente às demandas de mercado. Assim, o capital turismo, enquanto fruto do negócio-turismo ou da mercadoria turismo, apresenta-se eivado dos processos político-ideológicos de mercado em sua via globalizada.

Como resultado deste processo hegemônico as políticas públicas de modo mais geral e as de turismo, em particular, para os países que compõe a tríplice fronteira do Brasil, Colômbia e Peru adotam o receituário imputado pelo modelo global de desenvolvimento. Tal modelo está centrado no viés econômico que vê a Amazônia como grande mercado de commodities o que implica dizer que as políticas públicas advindas não são autônomas em relação aos processos globais. Assim, Brasil, Colômbia e Peru acedem a processos de conservação dos recursos naturais centralizados em vasta legislação ambiental que, apesar de reconhecida internacionalmente, não se realiza de facto.

Enfatiza-se que o turismo serve como corolário para mascarar ou suavizar a intenção primeira do capital que é a cooptação das populações locais - tradicionais ou não, indígenas ou não indígenas - ao processo de globalização. Resulta desse movimento conflitos visibilizados em lutas as mais diversas que, no caso dos indígenas, vão desde o reconhecimento de territórios até a fiscalização de atividades ilegais. Tal processo acontece nos três países sob o grau maior ou menor de tutela do Estado que contribui com a legalização de atividades poluidoras nos territórios indígenas como, por exemplo, a petroleira e a mineradora.

Desta feita a participação da população local nos processos de gestão é limitada ao desempenho de estratégias de fiscalização dos ilícitos e de coadjuvante da administração pública. Assim, a qualidade da participação fica prejudicada enquanto processo de gestão de tal sorte que as populações, tradicionais ou não, da Amazônia brasileira e mesmo as da Pan-Amazônia estão sendo cooptadas e não podem recuar a esse 
movimento. Nesse aspecto, pode-se inferir que a participação na gestão também é relativizada pelo grau maior ou menor de participação política dos grupos organizados.

Pode-se inferir que a qualidade da participação das populações na gestão é prejudicada por condições que dizem respeito ao próprio fazer turístico e pela visão distorcida da atividade impressa pelo Estado como redentora de todos os males. Tal fato ocasiona uma miopia das populações sobre o setor turístico que passa a vê-lo como a panaceia que irá alçar as condições de sustentabilidade econômica e social. Nesse sentido, nos três países pôde-se observar que essa premissa é validada, haja vista que a atividade foi imposta sem a devida reflexão do que seria possível para as comunidades.

\section{Referências bibliográficas}

ALBAGLI, S. Interesse global no saber local: a geopolítica da biodiversidade. In: SEMINÁRIO SABER LOCAL/INTERESSE GLOBAL: propriedade intelectual, biodiversidade e conhecimento tradicional na Amazônia, 1., 2005, Belém, Anais...Belém, CESUPA; MPEG, 2005. p. 17-27.

ALMEIDA, A. W. B de. Terras de quilombo, terras indígenas, "babaçuais livres", "castanhais do povo", faixinais e fundo de pasto: terras tradicionalmente ocupadas. Manaus: PGSCA; UFAM, 2008.

BECKER, B. K. Amazônia: geopolítica na virada do III milênio. Rio de Janeiro: Garamond, 2009.

BURSZTYN, I.; BARTHOLO, R.; DELAMARO, M. Turismo para quem? Sobre caminhos de desenvolvimento e alternativas para o turismo no Brasil. In: BARTHOLO, R.; SANSOLO, D. G.; BURSZTYN, I. (Org.). Turismo de base comunitária: diversidade de olhares e experiências brasileiras. Rio de Janeiro: Letra e Imagem, 2009.

CAMPOS, R. I. R. de. Sustentabilidade, turismo e gestão do patrimônio arqueológico: limites e possibilidades no Maracá (AP) e Serra dos Martírios/Andorinhas (PA). 2008. 396f. Tese (Doutorado em Desenvolvimento Sustentável)- Núcleo de Altos Estudos Amazônicos, Universidade Federal do Pará, Belém, 2008.

COUTINHO, L. M. O conceito de bioma. Acta Botânica Brasileira, São Paulo, v. 20, n. 1, p. 13-23, 2006.

CRUZ, J. G. da. Abordagem sociológica sobre os Tikuna no contexto contemporâneo. Manaus: Centro Cultural dos Povos da Amazônia, 2006.

CRUZ, S. H. R. Turismo, fronteira e desenvolvimento na Pan-Amazônia: trajetórias entre o Brasil e a Guiana Francesa. 2010. 369 f. Tese (Doutorado em Desenvolvimento Sustentável)- Núcleo de Altos Estudos Amazônicos, Universidade Federal do Pará, Belém, 2010.

FUTADA, S. de M. Avanços normativos e estruturais do SNUC na Amazônia Legal. In: VERISSIMO, A. et al. Áreas protegidas na Amazônia brasileira: avanços e desafios. Belém: IMAZON; São Paulo: Instituto Socioambiental, 2011. p. 36-42. 
GOVERNO DA COLOMBIA. Plan de Manejo Parque Nacional Natural Amacayacu - 2004. Disponível em: <http://www.parquesnacionale.gov.co>. Acesso em: 4 jun. 2013.

HOUSE, J. W. The frontier zone: a conceptual problem for policy makers. International Political Science Review, Internacional Political Science Association, v. 1, n. 4, p. 456-477, 1980.

INSTITUTO DE POLÍTICAS ECONÔMICAS APLICADAS - IPEA. A comissão nacional de desenvolvimento sustentável dos povos e comunidades tradicionais na visão de seus membros: relatório de pesquisa. Brasília, 2012.

INSTITUTO SOCIOAMBIENTAL - ISA. Lançados editais de terceirização de serviços turísticos em três parques nacionais. 29 mar. 2010. Disponível em: <http://www.socioambiental.org/noticias/lancado-editais-detercerizacao-de-servicos-turisticos-em-tres-parques-nacionais> Acesso em: 23 jun. 2015.

MACHADO, L. O. Cidades na fronteira internacional: conceitos e tipologia. In: CONFERÊNCIA INTERNACIONAL DESENVOLVIMENTO URBANO EM CIDADES DE FRONTEIRA, 2, 2007, Foz do Iguaçu. Anais...Foz do Iguaçu, 2007. p. 59-71.

MCKERCHER, B. Turismo de natureza: planejamento e sustentabilidade. 1.ed. São Paulo: Contexto, 2002. 303 p.

MILLER, K. R. Evolução do conceito de áreas de proteção: oportunidades para o século XXI. In: CONGRESSO BRASILEIRO DE UNIDADES DE CONSERVAÇÃO, 1; 1997, Curitiba, Anais... Curitiba: IAP; UNILIVRE; RNPUC, 1997. p. 3-21.

NABAROA LETURIA, N. Tikunas o Ticunas: cuatro propuestas ortográficas para una lengua. LIAMES - Lenguas Indígenas Americanas, p. 145-168, 2011.

OLIVEIRA FILHO, J. P. de. O nosso governo: os Ticuna e o regime tutelar. São Paulo: Marco Zero, 1988.

OLIVEIRA, R. C. de. Possibilidades de uma antropologia da ação. In: Sociologia do Brasil indígena. Rio de Janeiro: Tempo Brasileiro, 1978.

ORGANIZAÇÃO MUNDIAL DE TURISMO - OMT. Guia de Desenvolvimento do Turismo Sustentável. 1.ed. Porto Alegre: Bookman, 2003. $168 \mathrm{p}$.

QUARESMA, H. D. A. B. Turismo na terra de Makunaima: sustentabilidade em parques nacionais da Amazônia? 2008. 418 f. Tese (Doutorado em Desenvolvimento Sustentável) - Núcleo de altos estudos Amazônicos, Universidade Federal do Pará, Belém, 2008.

RESERVA NACIONAL PACAYA SAMIRIA. Plan de uso turístico y recreativo de la Reserva Nacional Pacaya Samiria. Iquitos: INRENA, 2002. 
SÁNCHEZ ALBAVERA, F. El actual debate sobre los recursos naturales. Revista de la CEPAL, Santiago de Chile, n. 51, p. 163-178, 1993.

SILVA, J. B. da; SIMONIAN, L. T. L. População tradicional, Reservas Extrativistas e racionalidade estatal na Amazônia brasileira. Desenvolvimento e Meio Ambiente (UFPR), v. 33, p. 163-175, 2015.

SIMONIAN, L. T. L. Tendências recentes quanto à sustentabilidade no uso dos recursos naturais pelas populações tradicionais amazônidas. In: ARAGÓN, E. (Org.). Populações e meio ambiente na Pan-Amazônia. 1. ed. Belém: NAEA/UFPA, 2007. p. 25-44.

SIMONIAN, L. T. L. Políticas públicas, desenvolvimento sustentável e recursos naturais em áreas de reserva na Amazônia Brasileira. In: COELHO, M. C. N., SIMONIAN, L. T. L., FENZEL, N. (Org.). Estado e políticas públicas na Amazônia. Belém: CEJUP, 2000. p. 9-53.

SIMONIAN, L. T. L.; PINTO, P. M.; CAMPOS, R. I. R. de. Unidades de conservação em Martírios/Andorinhas: perspectivas ambientais, socioeconômicas, culturais e turísticas. Belém: CSE; UFPA, 2007.

SISTEMA NACIONAL DE ÁREAS NATURALES PROTEGIDAS POR EL ESTADO - SINANPE. Plan maestro Reserva Nacional Pacaya Samiria 2009-2013. Para La conservación de la diversidad biológica y el desarrollo sostenible de la Reserva Nacional Pacaya Samiria y su zona de amortiguamiento. Iquitos: Lima, 2009.

TELES, R. M. de S. (Org.). Turismo e meio ambiente. 1. ed. Rio de Janeiro: Campus, 2011. $230 \mathrm{p}$.

Notas:

1 "Ao contrário do senso comum, este não é constituído por um tipo único de floresta, por um bioma único, em toda sua vastíssima extensão. Ali existem tipos diferentes de biomas, [...] floresta tropical pluvial, [...] floresta de igapó, inundável, [...] as caatingas do rio Negro, um bioma de savana arenosa, [...] os campos rupestres, como os dos picos das serras, nas fronteiras com países vizinhos, [...]. Ele é um mosaico de biomas" (COUTINHO, 2006, p. 18).

2 Para uma discussão acerca do conceito de comunidade, ver, dentre outros autores, Simonian (2007).

${ }^{3}$ Cita-se como exemplo o Núcleo de Altos Estudos Amazônicos (NAEA), da Universidade Federal do Pará (UFPA), bem como os do Museu Paraense Emílio Goeldi (MPEG). Aquele atuando mais profundamente na pesquisa em turismo, a partir dos anos 1990; e este com estudos baseados, principalmente, nas Ciências Humanas desde os anos 1970. Na PanAmazônia os realizados pela Universidad Nacional de Colombia (UNAL), sede Amazonía, a partir dos anos 2000. E os da Universidad Nacional de Amazonía Peruana (UNAP), desde 1999.

${ }^{4}$ Refere-se ao nome grafado no Decreto $\mathrm{s} / \mathrm{n}$, de 11 de dezembro de 1998, que homologou a demarcação administrativa dessa TI.

5 Uma tríplice fronteira é o lugar comum que une os limites territoriais e políticos de três países diferentes. As tríplices fronteiras da América do Sul são muitas. Só o Brasil possui nove tríplices fronteiras. A Colômbia tem três e o Peru quatro. A área também pode ser chamada de tripla fronteira, tres fronteras, fronteira tripartite ou trapézio amazônico, esta última mais utilizada no contexto do território colombiano. 
${ }^{6}$ É comum o aparecimento de núcleos urbanos simetricamente dispostos dos dois lados de um limite internacional em várias regiões do mundo, usualmente vinculado à posição privilegiada em relação às redes de comunicação. Dessa proximidade deriva intenso intercâmbio de pessoas, serviços, capitais e informação, mas de modo geralmente assimétrico, às vezes complementar, às vezes competitivo (HOUSE, 1980).

7 Especialmente, os missionários e os naturalistas.

${ }^{8}$ A posição geográfica das cidades em relação ao limite internacional permite distinguir as localizadas na linha de fronteira e na região de fronteira. O Brasil ratificou, através da Constituição de 1988, o polígono de $150 \mathrm{Km}$ a partir do limite internacional como área de segurança nacional ou faixa de fronteira (MACHADO, 2007).

9 Nome do Povo: Ticuna. Família Linguística: Tikuna. Outros nomes e grafias: Tikuna, Tukuna, Magüta. No contexto deste estudo, adotou-se nesta tese o nome da família linguística, mesmo porque existe um debate de cunho político, ainda em curso, sobre a unificação da grafia nos três países fronteiriços (NABAROA LETURIA, 2011).

10 De acordo com o Decreto n. 3.572/2011, a entidade está encarregada da administração e manejo do SPNN e da coordenação do Sistema Nacional de Áreas Protegidas (SINAP).

11 Conforme as anotações feitas por P. M. Pinto durante a disciplina Antropologia do Desenvolvimento ministrada por Ligia T. L. Simonian, em 2012, no contexto do Programa de Pós-Graduação em Desenvolvimento Sustentável do Trópico Úmido (PPGDSTU), do Núcleo de Altos Estudos Amazônicos (NAEA), da Universidade Federal do Pará (UFPA).

12 As normativas do SERNANP peruano adotam o termo Áreas Naturales Protegidas (ANP), enquanto que AP é usado oficialmente pelo SPNN colombiano. Por isso, adotar-se-á aqui a nomenclatura internacionalmente reconhecida de AP como modo de integração das análises.

13 Compreende todos os tipos de turismo realizados em espaços naturais. Nasce em oposição ao turismo tradicional (de massa) e envolve tipos variados de turismo alternativo. Nesse contexto, encontram-se os segmentos do turismo rural, de aventura, pesca, saúde e de sol e praia (TELES, 2011). Para McKercher (2002, p. 13), o turismo de natureza compreende "[...] ecoturismo, turismo de aventura, turismo educacional e uma profusão de outros tipos de experiências proporcionadas pelo turismo ao ar livre e alternativo".

14 Trata-se da Comissão Nacional de Desenvolvimento Sustentável das Comunidades Tradicionais, criada pelo Decreto de 27 de dezembro de 2004, a qual teve sua denominação, competência e composição alterada pelo Decreto de 2006.

15 "Nas duas últimas décadas estamos assistindo em todo o País, e notadamente na Amazônia, ao advento de novos padrões de relação política no campo e na cidade. Os movimentos sociais no campo, que desde 1970 vem se consolidando fora dos marcos tradicionais do controle clientelístico e tendo no Sindicato de Trabalhadores e Trabalhadoras Rurais uma de suas expressões maiores conhecem, desde 1988-89, certos desdobramentos, cujas formas de associação e lutas escapam ao sentido estrito de uma entidade sindical, incorporando fatores étnicos, elementos de consciência ecológica e critérios de gênero e de autodefinição coletiva, que concorrem para relativizar as divisões político-administrativas e a maneira convencional de pautar e encaminhar demanda aos poderes públicos" (ALMEIDA, 2008, p. 25).

16 "O fato dos legisladores terem incorporado a expressão "populações tradicionais" na legislação competente e do governo tê-la adotado na definição das funções dos aparatos burocrático-administrativos, tendo inclusive criado, em 1992, o Conselho Nacional de Populações Tradicionais, no âmbito do IBAMA, não significa exatamente um acatamento absoluto das reivindicações encaminhadas pelos movimentos sociais, não significando, portanto, uma resolução dos conflitos e tensões em torno daquelas formas intrínsecas de apropriação e de uso comum dos recursos naturais, que abrangem extensas áreas principalmente na região amazônica" (ALMEIDA, 2008, p. 26). Para uma discussão sobre o conceito de populações tradicionais, ver Silva e Simonian (2015). 
17 "Os conselhos de políticas públicas são aqui entendidos como espaços públicos vinculados a órgãos do Poder Executivo e têm por finalidade permitir a participação da sociedade na definição de prioridades para a agenda política, bem como na formulação, no acompanhamento e no controle das políticas públicas. São constituídos em âmbito nacional, estadual e municipal. Além disso, é importante ressaltar que eles permitem a inserção de novos temas e atores sociais na agenda política" (IPEA, 2012, p. 11).

Nota final: Este texto é um excerto da tese de doutoramento intitulada "Políticas públicas de turismo na Pan-Amazônia: processos de gestão local em áreas protegidas na tríplice fronteira do Brasil, Colômbia e Peru", apresentada em março de 2016 no âmbito do Programa de Pós-Graduação em Desenvolvimento Sustentável do Trópico Úmido (PPGDSTU), do Núcleo de Altos Estudos Amazônicos (NAEA), da Universidade Federal do Pará (UFPA), sob a orientação da Professora Ph. D. Ligia Terezinha Lopes Simonian.

Agradecimentos: à Coordenação de Aperfeiçoamento de Pessoal de Nível Superior (CAPES), através do Programa Institucional de Doutorado Sanduíche no Exterior (PDSE), pelo apoio financeiro sem o qual esta investigação dificilmente seria concluída.

Paulo Moreira Pinto: Universidade Federal do Pará, Belém, PA, Brasil.

E-Mail: pmpinto@ufpa.br

Link para o currículo Lattes: http://lattes.cnpq.br/6876291957759425

Data de submissão: 30 de agosto de 2016

Data de recebimento de correções: 16 de setembro de 2016

Data do aceite: 27 de novembro de 2016

Avaliado anonimamente 